\title{
Reviews
}

\author{
V.V. NALIMOV \\ Faces of Science \\ Edited by R.G. Colodny, ISI Press, Philadelphia, \\ 1981, 297 pages, Translation from the Russian
}

\author{
A.W. SMITH \\ Management Systems: Analyses and Applications \\ The Dryden Press, Hinsdale, IL, 1982, 429 pages

\section{D.V. STEWARD} \\ Systems Analysis and Management: Structure, \\ Strategy, and Design \\ Petrocelli, Princeton, NY, 1981, 287 pages
}

Reviewer's Comments. The three books reviewed here together show the wide range of publications in the systems field. It varies from the highly philosophical treatise to the eminently practical manual for systems analysts. I renew my plea to readers to send their book reviews or suggestions for books to be reviewed to the Book Review Editor.

The author of Faces of Science is a well-known mathematician and cyberneticist. $\mathrm{He}$ is a member of the Scientific Council of Cybernetics and Director of the Laboratory of Mathematical Theory of Experiment of Moscow State University. Faces of Science is a compilation of probing essays which have been published in Soviet scientific journals, some in foreign ones. Each of the papers reflects a different aspect of science according to the author:

\footnotetext{
Man is revealed through his vision of the world. Science, in the dialectical opposition of the logical versus the illogical, reflects human nature rather than the nature of that world described by. man. Therefore, the study of the nature of science is primarily a way of understanding man. (p. xii)
}

North-Holland Publishing Company

Human Systems Management 3 (1982) 219-224
Nalimov undertakes to discuss several questions which concern modern epistemologists. As a start, he contrasts Popper and Kuhn's viewpoints about how science grows. Nalimov imagines an open dialogue with Popper and proceeds to strengthen Kuhn's statements on the role of the paradigm in science by using Bayesian concepts. Kuhn's 'greatest merit' is said to be the introduction of the paradigm notion "as an intellectual field driving the development of a particular branch of knowledge in one strictly defined direction and protecting it from the destructive influences of other possible approaches".

Later on, Nalimov proceeds to discuss Gödel's theorem and its significance for modern mathematics. Given that "all generally used logical systems in which arithmetic is expressible are incomplete, if they are inconsistent", the need for metamathematics arises. "The subject of metamathematics are statements about the formal systems of mathematics, i.e., the statements about its structures and its logical deductions and its formulas".

Nalimov reminds us that in "attempting to reconstruct any branch of knowledge", we must distinguish between three stages of formalization: mathematization, axiomatization, and the construction of interpretative rules. Unfortunately, attempts to axiomatize physics and mechanics can be qualified as of limited success.

Concerning the question of "Why do we use probabilistic concepts to describe the world", Nalimov recognizes that the weakening of determinism, the acceptance of chance and randomness, as well as attempts to construct a many-valued logic must be acknowledged as progress in comprehension and thinking. Nalimov then leads directly to a consideration of the next natural development - that of Fuzzy Sets.

The concept of Fuzzy Sets was introducted by L. Zadeh and Nalimov sketches a hypothetical dialogue with this author. "Zadeh, doing justice to the pioneer papers by Weiner and Shannon, who showed information to be internally statistical, em- 
phasizes that lately there have emerged problems generally related to the sense of information rather than to its transmission as a symbolic system by a channel". According to Nalimov, Zadeh states that, "in solving these problems, one has to proceed from the distribution of possibilities rather than from probability theory. The distribution of possibilities follows from the conception of Fuzzy Sets and is, perhaps, the central idea of this theory". Nalimov attempts to outline a metatheory for the probabilistic approach to the theory of Fuzzy Sets and asks, "Is not the probabilistically-weighted vision of the world a realization of the dream of Pythagoras and Plotinus of describing the world in its integrity and fuzziness through numbers?" "... So perhaps the fuzzy, probabilistically-weighted vision of the world is the restoration of Ancient Greek numerical dialectics".

Nalimov then proceeds in his book to apply the cybernetic approach to the study of complex systems. He presents the outlines of a formal analysis of theoretical biology, as an example of the problem of describing complexity in the scientific world.

In one of the last chapters, Nalimov reflects on the penetration of the humanities into scientific disciplines and, paradoxically, uses the words of Lewis Carroll to describe the human experience compared to the "cosmic destinies of the worlds, civilizations, and biospheres". "... You're sure to [get somewhere] ... if you only walk long enough".

The author then tackles the ecological problem which he states "has acquired apocalyptic overtones". "Is Science ready to solve this problem?", he asks. "To answer this question we must understand whether scientific forecasting is possible, whether scientific ideas can influence social behavior, whether the historical origin of this crisis can be scientifically analyzed, and whether a scientific approach to setting a global goal is possible".

The two final chapters of this compilation of articles are concerned with:

(1) the distribution of scientific information, and

(2) the social demands for intellectuals.

They are certainly not as important as the questions raised by Nalimov in his conclusion. There, he raises thought provoking questions which may be the most important of his book. They are concerned with the issues of knowledge and the mastery of the world through the infinite process of science. Science is in perpetual evolution whereby its participants are perpetually faced "with new, more and more complicated problems, which in turn, allow a glimpse of the new mysteries of the world". "We have to acknowledge with a certain amazement that the depths of our unconscious are remarkably bottomless". Science is not so much cognition of the world, but rather "the deepening of our interactions with the world, accompanied by the expansion of our consciousness".

Nalimov's Faces of Science suffers from one important shortcoming. It is the fact that, while this book is a compilation of many articles which have been gathered around a common theme, the integration is still rather weak. The impression of this reviewer is that too many complex subjects are covered in a rather superficial manner. The English translation, while excellent, probably does not convey the rich meaning of the original. One needs to mention Zlatkovsky's illustrations which provide surrealistic renditions of Nalimov's ideas. These illustrations, with their respective insightful captions, could easily be the subject of an art exhibit.

On the whole, the book must be recommended as an overwhelming treatise of the problems of modern science, its quests, its visions, its successes, and naturally, of its failures.

August W. Smith's Management Systems is a worthwhile addition to the number of college texts devoted to the subject of the Systems Approach. There was a time, not so long ago, when books on this topic would be treated as original and novel and published only as reference material. (As an example, Churchman's The Systems Approach was published in 1968.) Smith's book is a college text and, as such, is a vivid reminder that systems theory has now 'arrived'.

The book conceived by Smith is a hybrid combination of general systems theory, organization theory, and management information-controlplanning systems.

Part One (The Systems Approach to Management) is devoted to an introduction of systems concepts and systems terms. Systems thinking is compared to the reductionist linear approach. Systems Design is compared to Systems Improvement and to Systems Innovation. The differentiation among state-maintaining, goal-seeking, multigoalseeking/purposive, and purposeful systems is discussed. Systems interventions and dynamics in terms of black, grey, and white box models are 
explained. A chapter is devoted to measurement scales and models where the importance of qualitative as well as quantitative evaluation is emphasized.

Part Two deals with organizations as dynamic systems and as purposeful systems. Here are treated the characteristics of environmental and organizational structure, centralization/decentralization, optimization/suboptimization, tradeoff analysis, and the evaluation of strategies and tactics.

Part Three is devoted to Decision-Support and Management-Information Systems. The nature of decision making and of decision-making paradigms and styles is discussed. Information is examined as a resource to be managed, analyzed, and accessed. Data and information systems are described as an introduction to MIS design and development.

In Part Four, Smith considers planning and control systems. He successfully identifies the types of managerial responses to various types of environments. He then introduces the elements of cybernetics in relation to managerial control.

Readers who expect to find in this book traditional philosophical and epistemological cogitations on general systems issues will be disappointed. However, those who need a straightforward college text to explain what the Systems Approach is all about will be well served. August W. Smith has done his job well. He may not be a philosopher, but he is probably an excellent teacher. If the Systems Approach and systems science are to graduate from the realm of obscure conferences to that of the classroom, more books in the mold of the present one will have to be published. It always takes courage for a publisher to undertake a project such as this one. The Dryden Press must be commended. The text is well printed and the illustrations, which are numerous, are well executed. We should not forget to mention that there are also about a dozen short cases at the end of the text to facilitate discussion. One possible weakness of the book resides in its attempt to cover too many subjects. As an author, I understand the dilemma in which Smith found himself: what to include and what to leave out. He struck a happy balance and we hope that the market will reward him with the success he deserves.

D.V. Steward's Systems Analysis and Management is an eminently practical book which develops methods to represent and to study the struc- ture of a system, while developing strategies to design and manage it.

In the language of the author, "systems can be described by their structure and semantics. The structure is represented by a graph or matrix showing the interrelationship among its parts, i.e., where the parts are connected, or related. The semantics are concerned with how and why the effects occur',".

The methods presented by the author can be used to make changes in complex systems to obtain a particular desired result. Once the structure of a problem has been elicited through the precedence table and the corresponding matrix, the relationship among the factors involved becomes evident. Analysts can proceed to make changes in the existing conditions to study their implication. By a series of iterations and manipulations, they can identify direct and indirect effects and intervene to influence them. A computer program can be used to generate all indirect effects to recognize their impact. Changes can be made to accomplish a particular goal and predict their consequences. A list of possible actions can be simulated to follow cause-effect relationships and develop possible action plans. The possibility of changing relations among factors and the conditions affecting the problem can also be investigated. The system description can be simplified by combining closely related conditions as evidenced in the matrix. Thus, the structural mode developed by Steward and its attendant methodology should prove an invaluable tool to evaluate complex socio-economic situations. With it, one can obtain a clear mapping of the problem, evaluate possible changes, the costs of making these changes, and the resultant benefits. The methodology should be particularly useful for designers and planners to document and communicate aspects of systems design with their manager counterparts.

Readers will want to read this book for different purposes. Some will want to delve in detail into the original methods presented. Others will be interested to think about some of its implications. I count myself among the latter. Given that we are cursed by the complexity of systems, we need methods by which large systems can be broken down into smaller systems, without losing sight of interrelationships and interfaces.

The author is well qualified to write about this subject. One of his recent articles [1] drew an avid response. 
This book fits a clear-cut need in the systems literature. It does not entertain lengthy philosophical discussions. It is a 'hands-on' manual which will appeal to development and production engineers and scientists who want to apply the systems decomposition methods to their own problems. It will also appeal to systems theorists and analysts who seek to grapple with the intricacies of large social systems and to find ways to improve their cost-effectiveness. The text is well documented. The presentation is clear and pitched to the layperson by providing step-by-step instructions on how to proceed.

John P. van GIGCH California State University Sacramento, CA 95819 U.S.A.

\section{Reference}

[1] D.V. Steward, The design structure system: A method for managing the design of complex systems, IEEE Trans. Engrg. Management 28 (1981) 71-73.

Jacques LESOURNE

Les Mille Sentiers de L'Avenir (The Thousand Paths of the Future)

Editions Seghers, Paris, 1981

"At the beginning, almost a decade ago, a feeling of revolt. Revolt against the ingenuity of political discourse, against the unsufficiency of the accepted interpretations of social events, against the ignorance displayed by science when interpreting the evolution of societies. As a result, the language of systems offered a tentative effort of synthesis. The choice of that language was not guided by a willingness to superimpose an additional classification upon the specialized knowledge of the various sciences, but the result of the conviction that all sciences are trying, in their own way, to build a systemic approach to represent the reality which they study which they can claim their own. What is then a system?"

This is how Jacques Lesourne describes the program which he set for himself to render the paths to the future intelligible (p. 15). We are familiar with the exceptional experience, the uni- versality of culture, and the openmindedness of Jacques Lesourne, engineer-economist, scholar, and man of action. It is not necessary to introduce him any further, except to remind readers of his continuous interest for the contemporary development of Systems Theory, an interest which he revealed five years ago in Les Systèmes du Destin, Dalloz, 1976.

Les Mille Sentiers de L'Avenir is presented more like an essay than a treatise, or a thesis. It is a deliberate, personal essay which liberates his author from the institutional constraints which used to influence too much his own perceptions. It is a personalized essay whose conclusions and arguments will often (but not always) convince its readers. The essay is fascinating because of its methodology and the facility of expression with which questions are posed, problems diagnosed, and the information organized. One could complain that the methodology used is more intuitive than explicitly systemic.

Les Mille Sentiers de L'Avenir can also be interpreted as an essay about a thousand methods, without any reference to Aristotle, Descartes, von Bertalanffy, or Piaget.

Lesourne reminds us that the objective of this essay is not "to astonish or to reassure" his audience, but rather, to make what is possible, intelligible in its diversity. Could there be a better definition of the (so-called) 'prospective' Futurology: "To make 'the possibles' intelligible in their diversity?"

It is noteworthy to cite how Lesourne envisages this action:

The future of industrial societies will result much less from the scarcity of their physical resources than from transformations of the international system and of the forces of change internal to these societies. With the relative decline of the superpowers and the advance of the Third World, the international system is becoming multipolar and interdependent and, thus, the source of uncertainties and of vulnerability for each country. Simultaneously, the industrial societies are the focus of changes of values which propel social demands and of an increase of rigidities which render adaptations more difficult.

The methodology is global and systems oriented. This essay should be considered a lasting and important contribution to Futurology, one of the newest disciplines extant. To be entirely convincing, the discussion will have to be extended from its present format in order to remedy the 
rather short treatment of his proposed solutions for inflation and unemployment (p. 354). One can also regret the author's apparent indifference toward major technological risks, such as that posed by the development of nuclear power, and the superficial coverage of other important scenarios for the future. It is easy for the reviewer to speculate about some methodological improvements which could be applied to this work. It is possible that Jacques Lesourne hesitated to take advantage of relatively recent advances of Systems Theory, in particular, the modeling of autonomous systems and that of the informational role of complex systems. These approaches may have led to a difficult view on many subjects. However, it is to the merit of Lesourne to raise these questions and invite us to participate in their debate. ${ }^{1}$

\section{J.L. Le MOIGNE Faculté d'Economie Appliquée Université de Droit, d'Economie et des Sciences 13100 Aix-En-Provence, France}

Translated by John P. van GIGCH California State University Sacramento, CA 95819, U.S.A.

1 This review appeared in Systemique Informations, No. 10 , February 1982, Paris, AFCET (Association Française pour la Cybernétique Economique et Technique). Used with permission.

\section{D.N. ROBINSON}

Psychology and the Law: Can Justice Survive the Social Sciences?

Oxford University Press, New York/Oxford, 1980, 221 pages

The publication of Robinson's Psychology and the Law: Can Justice Survive the Social Sciences? could not be more timely. We have just recently read the account and the verdict of the Hinckley trial which illustrates so pointedly the ideas which Robinson attempts to put across.

It is interesting to note the publication in the daily press of two commentaries by Robinson [1,2]. One was written after President Reagan's shooting and before his assailant's trial. The second appeared after the court's decision. In both,
Robinson raises the following points which are also central to his book.

$\mathrm{He}$ argues that justice is not served with the contemporary interpretation which the courts place upon the insanity plea.

He starts from the argument that, in such cases, insanity is related to innocence as sanity is to guilt. In modern jurisprudence, Robinson deplores the fact that in order to prove guilt, the government and the prosecutor must prove sanity "beyond a reasonable doubt". However, states Robinson, to prove sanity is as hard as to prove health. How can one ever 'prove' health? To ask "Is Smith sane" is more akin to asking, "Is Smith virtuous" than "Does Smith have tuberculosis?" In other words, to establish that Smith has tuberculosis, established diagnostic standards exist, whereas no such standards exist in matters of virtue or in matters of mental health.

At this point, Robinson strongly berates the so-called testimony of experts and in particular that of psychiatrists and psychologists:

Since there is no settled body of fact, no settled and reliable methods of measurement, and not a single theoretical term that has ever been vindicated by accepted modes of scientific verification, clinical psychologists and psychiatrists cannot be said to occupy a space within which expertise can flourish. And, where there cannot be expertise, there cannot be 'expert testimony'. [2]

In this book, Robinson not only attacks psychiatrists and psychologists but all of the social sciences whose claims to be considered sciences are, according to him, 'utterly unwarranted'. To make his point he chose a small number of jural questions where the administration of justice was influenced by the psychosocial point of view, i.e., "jural settings in which psychologists and psychiatrists have come to take a leading part".

"Today's ruling faction is environmentalism [where] the contemporary court listens with hushed attention as psychiatrists and psychologists recount the woes of early neglect, friendlessness, poverty, and those other 'determinants' of criminality". [1]

What needs to be done, according to Robinson, is to separate scientific theory which can explain human conduct in terms of the physiology and biochemistry of the brain, and [environmentalism] or 'folk theory' where all significant human actions proceed from a defendant's personal history. 
Whereas, the scientific theory can provide facts, the 'folk theory' is only belief and opinion.

Robinson provides 'modest proposals' to treat psychiatric and psychological testimony in cases of criminal insanity. These proposals relate to whether statements admitted to evidence are to be treated as facts, opinions, or belief. He asks the courts to discount the expert testimony of social science experts and then, ventures into the length of sentences which defendants, claiming insanity, ought to serve when found guilty under criminal statute.

The whole of Robinson's thesis is interesting and all the more fascinating at a time when public opinion and the media are digesting the news of the Hinckley verdict.

Two important questions stand out in the mind of the present reviewer not knowledgeable in points of law.

(1) This is not the first or the last attempt to discredit the social sciences and social scientists. The social sciences are young and must, without a doubt, improve its theories and methodologies. Among the social sciences, the systems movement has tried to provide new approaches and new tools to enhance their credibility. Without a doubt, those who overstate these claims deserve to be branded by the likes of Robinson. His 'broadsides' are hardly justified given that the cannons of justice and its administration are, themselves, to be considered an integral part of the social sciences, the very territory he so liberally attacks.

(2) A fine line separates the neurological from the behavioral. To call statistics and the 'biochemical or neurological findings' established by medical science relevant evidence, and to reject as 'hocus-pocus' the behavioral, psychological, and psychiatric findings of social scientists, is to set back our standards of ethics and of fairness.

J.P. van GIGCH

California State University Sacramento, CA 95819, U.S.A.

\section{References}

[1] D.N. Robinson, The insanity defense and the Reagan shooting, Wall Street Journal, April 8, 1981, editorial page.

[2] D.N. Robinson, The Hinckley decision: Psychiatry in court, Wall Street Journal, June 23, 1982, editorial page. 